\title{
Molecular Evidence That Strain BV-15 of Peanut Stunt Cucumovirus Is a Reassortant Between Subgroup I and II Strains
}

\author{
C.-C. Hu and S. A. Ghabrial
}

Department of Plant Pathology, University of Kentucky, Lexington 40546-0091.

Accepted for publication 25 October 1997.

\begin{abstract}
Hu, C.-C., and Ghabrial, S. A. 1998. Molecular evidence that strain BV15 of peanut stunt cucumovirus is a reassortant between subgroup I and II strains. Phytopathology 88:92-97.

In Northern hybridization assays, RNA1 of peanut stunt virus (PSV) strain BV-15 hybridized strongly with a cloned cDNA probe to RNA1 from strain PSV-W (subgroup II). Cloned probes to PSV-W RNA2 and RNA3, however, did not hybridize with the corresponding RNAs from strain BV-15. The complete nucleotide sequence of PSV-BV-15 RNA2 has been determined, and sequence comparison analysis showed that it is

PSV subgroup I and II strains were 90.5 and $75 \%$, respectively. The possibility that PSV-BV-15 RNA2 may contain short regions derived from a subgroup II strain (i.e., represent a mosaic structure indicative of recombination) was investigated. Results indicated, however, that the entire PSV-BV-15 RNA2 sequence is derived from a subgroup I strain. PSVBV-15 RNA3 has previously been shown to belong to subgroup I strains. These results thus establish that PSV strain BV-15 is a natural reassortant between PSV subgroups I and II strains. A reverse transcription-polymerase chain reaction assay is proposed for differentiating between this reassortant strain and PSV strains in subgroups I and II.
\end{abstract} closely related to PSV subgroup I strains; the percent nucleotide sequence identity between PSV-BV-15 RNA2 and RNA2 sequences from
Additional keywords: genetic variability, reassortment.
Peanut stunt virus (PSV) is an economically important pathogen of legumes worldwide $(11,28)$. PSV is a member of the genus Cucumovirus in the family Bromoviridae (20). Other members of the genus are tomato aspermy virus (TAV) and the type member cucumber mosaic virus (CMV). Cucumoviruses have tripartite genomes of positive-strand RNAs, designated RNA1, RNA2, and RNA3 in order of decreasing size, that are packaged in isometric particles of about $28 \mathrm{~nm}$ in diameter. In addition to the genomic RNAs, the virions also encapsidate a fourth RNA (RNA4), a subgenomic 3'-coterminal with RNA3, that functions as mRNA for the viral coat protein (17). A small overlapping gene (2b), encoded by RNA2, was recently discovered in all cucumoviruses sequenced to date and is most likely expressed through the subgenomic mRNA RNA4A (3). Naturally occurring virions of CMV and PSV, but not TAV, may also package a fifth RNA, designated satellite RNA (satRNA), along with their genomic and subgenomic RNAs (13, 15,19).

On the basis of gel double-diffusion immunoassays and nucleic acid competition hybridization, isolates of PSV have been grouped into two major strains, eastern and western $(2,11,12,28)$. Recently, eastern and western strains (or subgroup I and II strains, respectively) were further differentiated based on Western and Northern blot assays and percent nucleotide (nt) sequence identity $(6,16)$.

The BV-15 strain of PSV has been reported to have nonoverlapping partial sequence similarity with both subgroups I and II in competition hybridization experiments (2). The finding that a RNA3specific probe from a subgroup I strain (16), but not from a subgroup II strain (6), hybridized strongly to PSV-BV-15 RNA3 and RNA4 is in agreement with the conclusion that strain BV-15 is serologically closely related to subgroup I in Western blotting assays (6). Although RNA1 of PSV-BV-15 did not hybridize to a RNA1specific probe from a subgroup I strain (PSV-ER), PSV-BV-15

Corresponding author: S. A. Ghabrial; E-mail address: saghab00@ukcc.uky.edu

Publication no. P-1997-1201-01R

(C) 1998 The American Phytopathological Society
RNA2 hybridized with a RNA2-specific probe derived from the same strain. The hybridization signal, however, was weaker than that observed in the homologous reaction (16). It was thus proposed that RNA1 of strain BV-15 is derived from a subgroup II strain and RNA3 from a subgroup I strain. The origin of PSV-BV15 RNA2, however, is unclear. The uncertainty about the origin of RNA2 was reinforced by the results of reverse transcription-polymerase chain reaction (RT-PCR) experiments in which a primer pair specific for PSV RNA2 was used (16). Whereas an RT-PCR product of the expected size $(1.2 \mathrm{kbp})$ was obtained with strains PSV-ER (subgroup I) and PSV-W (subgroup II), three RT-PCR products including the 1.2-kbp product and two smaller fragments were produced with strain BV-15 (16). The properties of RNA2 of strain BV-15 are thus typical of neither subgroup I nor II strains and may represent the product of intermolecular recombination involving RNA2 sequences from both PSV subgroups or from PSV and other cucumoviruses.

In this paper, we compare the complete nt sequence of RNA2 from strain BV-15 with that from subgroup I and II PSV strains and present molecular evidence that strain BV-15 is an intraspecific reassortant between subgroup I and II PSV strains.

\section{MATERIALS AND METHODS}

Virus strains and purification. The sources of PSV strains $\mathrm{ER}, \mathrm{W}$, and BV-15 were as described previously (16). All PSV strains were maintained in cowpea (Vigna unguiculata (L.) Walp. 'Blackeye') and increased in Burley tobacco (Nicotiana tabacum L. 'Ky 14') or cowpea. Purification of PSV virions was as described by Ghabrial et al. (4).

Northern hybridization analysis. Viral RNAs were extracted from purified virions as described by Naidu et al. (16), denatured with $6 \%$ formaldehyde, and separated by electrophoresis in $1.5 \%$ agarose gels made in TBE (89 mM Tris-borate buffer, $\mathrm{pH} 8.3$, containing $25 \mathrm{mM}$ disodium EDTA). The RNAs were then transferred and fixed onto Hybond-N membrane (Amersham Corp., Arlington Heights, IL) according to the manufacturer's instruc- 
tions. The membranes were prehybridized for $2 \mathrm{~h}$ at $42^{\circ} \mathrm{C}$ in a solution containing $5 \times \mathrm{SSC}(1 \times \mathrm{SSC}$ is $150 \mathrm{mM} \mathrm{NaCl}$ plus $15 \mathrm{mM}$ sodium citrate), $50 \%$ formamide, $0.5 \%$ sodium dodecyl sulfate (SDS), and $100 \mu \mathrm{g}$ of salmon sperm DNA per ml. Membranes were then hybridized with ${ }^{32} \mathrm{P}$-labeled probes prepared by nick-translation of full-length cDNA clones of PSV-W RNA1 (pW1), RNA2 (pW2), or RNA3 (pW3) for 16 to $18 \mathrm{~h}$ at $42^{\circ} \mathrm{C}$, followed by washing four times with $2 \times \mathrm{SSC}$ with $0.1 \% \mathrm{SDS}$ at $25^{\circ} \mathrm{C}$ for $15 \mathrm{~min}$ and 2 times with $0.1 \%$ SSC with $0.1 \%$ SDS at $68^{\circ} \mathrm{C}$ for $15 \mathrm{~min}$. The membranes were then air-dried and exposed for 5 to $12 \mathrm{~h}$ to Bio-Max film (Eastman Kodak Co., Rochester, NY) with intensifying screens at $-80^{\circ} \mathrm{C}$.

cDNA synthesis and cloning. RNA2 from PSV-BV-15 was purified from low-melting-point agarose following electrophoresis of unfractionated virion RNAs. A cDNA library representing RNA2 was synthesized using components of the Amersham cDNA synthesis kit (Amersham Corp.). Poly(A) tails were added enzymatically to PSV RNA2 by treatment with poly(A) polymerase (25), and cDNA synthesis was primed with oligo(dT) $)_{12-18}$ primers. Additionally, a $21 \mathrm{mer}$ synthetic oligonucleotide complementary to the 3'-terminal sequence of PSV-ER RNA4 (14) was used to prime the synthesis of first-strand cDNA. Second-strand cDNA was synthesized according to the procedure of Gubler and Hoffman (5). Double-stranded (ds) cDNA was blunt-ended with T4 DNA polymerase and ligated into SmaI-linearized pUC119 or pUC118. Selection of ampicillin-resistant cDNA clones containing inserts was made by blue/white colony screening on 5-bromo-4-chloro-3indolyl- $\beta$-D-galactopyranoside/isopropyl- $\beta$-D-thiogalactopyranoside medium (22).

Sequence analysis. Multiple independent cDNA clones of appropriate size were used for sequencing. For DNA sequencing analysis, ds-cDNA as well as single-stranded (ss) DNA of both strands of selected cDNA clones subcloned in the phagemids pUC118/119 and generated with the aid of helper phage (26) were used. Furthermore, nested sets of unidirectional deletion mutants of selected cDNA clones (subcloned in M13EcoK vector) were generated according to the procedure of Shen and Waye (24) and using the M13 single-step nested deletion kit (Bio 101, Inc., Vista, CA). Nucleotide sequences of selected cDNA clones were obtained with the dideoxy-chain termination method (23) using T7 DNA polymerase (Sequenase v. 2; United States Biochemical Corp., Cleveland) and ss- and ds-cDNA templates. As sequences were generated using universal sequencing primers, a directed sequencing protocol using progressive synthetic oligonucleotide primers was followed. At least two independent clones were sequenced from both orientations for each region of the cDNAs. The 5'-terminal sequences were determined by the dideoxy-chain termination method using a reverse transcriptase RNA sequencing kit method (United States Biochemical Corp.). An internal primer complementary to nt positions 101 to 117 was used to prime reverse transcription of the template RNAs. The sequences were assembled using the "GEL" program in the IG-Suite (IntelliGenetics, Inc., Mountain View, CA) and analyzed using both the IG-Suite and the University of Wisconsin GCG package (1). The GAP, PILEUP, and PRETTY programs in the UWGCG package (version 8.0) were used to align and compare nt and deduced amino acid (aa) sequence identities (and aa sequence similarities) between RNA2 sequences of the following PSV strains (GenBank accession number in parenthesis): PSV-W (U33146), PSV-BV-15 (U83332), PSV-ER (U15729), and PSV-J (D11127).

RT-PCR. RT-PCR assays using PSV RNA2 as template were performed as described by Naidu et al. (16). The sense (PSVER2f) and antisense (PSVER2r) primer pair, previously shown to direct the amplification of a PCR product of $1,171 \mathrm{bp}(16)$, was used. The PCR products were cloned using the pCR-Script Cam SK(+) cloning kit (Stratagene, Inc., La Jolla, CA) according to the manufacturer's instructions. Nucleotide sequences of the PCR clones were determined as described above.

\section{RESULTS}

Northern blot analysis. A typical ethidium bromide-stained denaturing agarose gel depicting the separated RNAs from three PSV strains is shown in Figure 1A. Northern blots of total RNAs from purified virions of PSV strains W (subgroup II), ER (subgroup I), and BV-15 were probed with cloned cDNA probes to PSV-W RNA1, RNA2, or RNA3. Whereas the PSV-W RNA1specific probe hybridized strongly with RNA1 from strains $\mathrm{W}$ and BV-15, it did not react with RNA1 from PSV-ER (Fig. 1B). On the other hand, the PSV-W RNA2- and RNA3-specific probes hybridized only with their homologous RNAs (Fig. 1C and D). As predicted, the PSV-W RNA3 probe also reacted with its homologous RNA4 (Fig. 1D).

Nucleotide sequence analysis of PSV-BV-15 RNA2. The complete nt sequence of a full-length cDNA clone of PSV-BV-15 RNA2 is shown in Figure 2. PSV-BV-15 RNA2 is 2,942 nt in length and contains two overlapping open reading frames (ORFs), $2 \mathrm{a}$ and $2 \mathrm{~b}$, corresponding to the sequences from nt 81 to 2,585 and from nt 2,392 to 2,682, respectively. The lengths of the coding and noncoding regions of strain BV-15 RNA2 (Fig. 2) were comparable to those of PSV subgroup I strains, PSV-J (7) and PSV-ER (C.-C. Hu and S. A. Ghabrial, unpublished data). Like other subgroup I strains, RNA2 of strain BV-15 has a longer ORF $2 b$ (291 nt) than that of the subgroup II strain W (198 nt) (C.-C. Hu and S. A. Ghabrial, unpublished data).

Sequence comparisons and search of PSV-BV-15 RNA2 sequence for intermolecular recombination. Comparisons of the PSV-BV-15 RNA2 nt sequence and the deduced aa sequence of ORF 2a to those of subgroups I and II of PSV (Fig. 3A) revealed that strain BV-15 is more closely related to subgroup I strains (PSV-ER and PSV-J, with over 90\% nt and aa sequence identities) than to the subgroup II strain PSV-W (less than 78\% identity). These results thus present conclusive evidence that strain BV-15 RNA2 is derived from a PSV subgroup I strain.

Although sequence comparisons indicated that PSV-BV-15 RNA2 is closely related to RNA2 of PSV subgroup I strains, the possibility that it may still contain short regions derived from subgroup II strains (i.e., a recombinant) could not be ruled out. To further investigate this possibility, the RNA2 nt sequence of PSV-

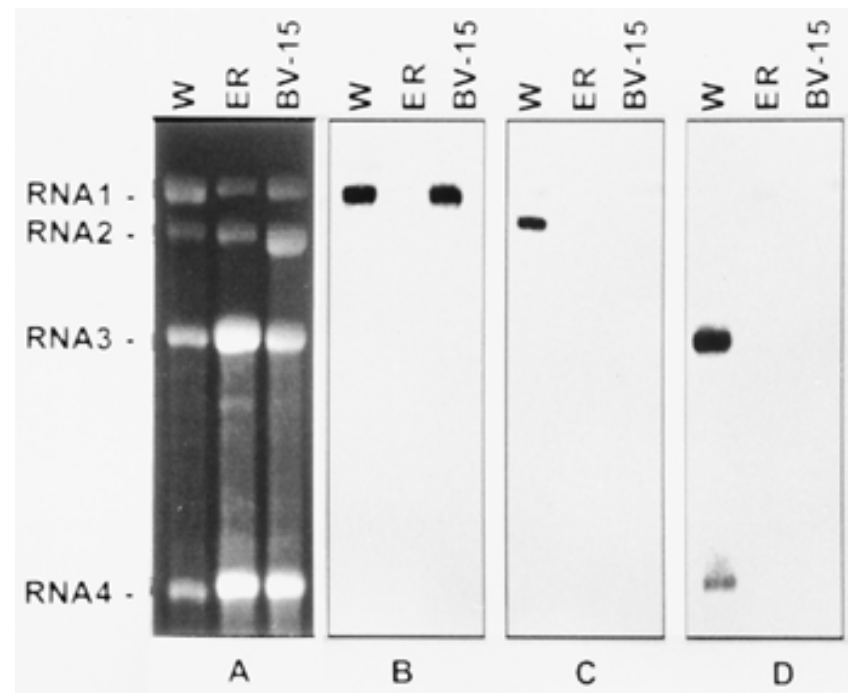

Fig. 1. Northern hybridization analysis of RNAs from representative strains of peanut stunt virus (PSV). Total virion RNAs were purified, separated by agarose gel electrophoresis (panel A), and transferred to Hybond-N membrane. The membranes were then probed with ${ }^{32} \mathrm{P}$-labeled cloned cDNA probes specific to PSV-W RNA1 (panel B), RNA2 (panel C), or RNA3 (panel D), washed, and exposed to X-ray film for $16 \mathrm{~h}$. The designations of the PSV strains from which the RNAs were extracted are marked on top of each lane. The positions of RNAs 1,2,3, and 4 are indicated on the left. 
BV-15 was divided into 42 overlapping fragments of equal length (70 nt including a 25-nt overlap with the downstream fragment), except for the fragment nearest the $3^{\prime}$ end (fragment 42), which was $72 \mathrm{nt}$ in length. Each fragment was then compared with the corresponding fragments of RNA2 sequence from PSV-ER and
PSV-W using the GAP program. The percent nt sequence identity values were used to evaluate the relatedness of PSV-BV-15 to the other two PSV strains. The results are shown graphically in Figure $3 \mathrm{~B}$. If strain BV-15 RNA2 is a recombinant between the RNA2 molecules from strains in the two subgroups, then some regions of
GTTTTATCAAGAGCGTACGGTTCAACCCCTGCCTCCTCTGATTTGCCAACTCCTCAGTTTTCTATATCTGTTAAGTTCTT ATGGCTACTTTCTCCCTTGAGTCCCTGTTATCAGGTGCTTACGGTGTTGACACTCCCGAAGAAGTAGCCTTTATTAGAGA

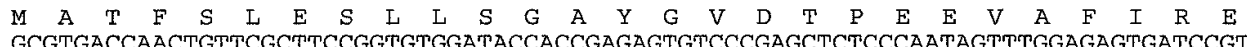
$\begin{array}{llllllllllllllllllllllllllllllll}R & D & Q & I & F & A & S & G & V & D & T & T & E & S & V & P & S & S & P & N & S & L & E & S & D & P & C\end{array}$

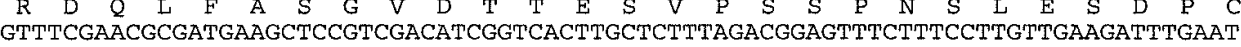

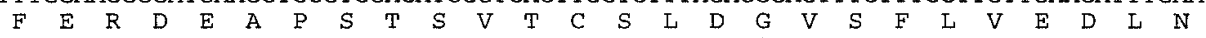
GCCATGTCTGACGTCGAGATTAAGACCGTCTTTGAGAATTTGATCAGGCCGACTTACGTAGGCTGTATTGAGGTACCTGA $\begin{array}{llllllllllllllllllllllllllll}A & M & S & D & V & E & I & K & T & V & F & E & N & L & I & R & P & T & Y & V & G & C & I & E & V & P & E\end{array}$ ATTTTGCAGGAACAAATTGACACTTAGCGTGTCCGTGGCTCGTAACCTCATCAGCACTGCTTCTAGGTATCCCCGTAAGT

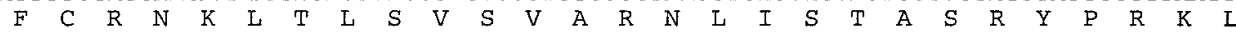
TAAAGGACTATCCTGATCTTGTTGCATCAATTTATAATGGAGCCGATATCTTTGATGATGCACTGGTCGATGAGACCATC $\begin{array}{lllllllllllllllllllllllllllll}K & D & Y & P & D & L & V & A & S & I & Y & N & G & A & D & I & F & D & D & A & L & V & D & E & T & I\end{array}$ TCAGACGAAGTTCCCGGGTACGTATTTCTTCCCGTGGAAAGACCTGACGGCTACGAGCGACCCCCGCTATGCTCAGACTG $\begin{array}{lllllllllllllllllllllllllllllll}S & D & E & V & P & G & Y & V & F & L & P & V & E & R & P & D & G & Y & E & R & P & P & L & C & S & D & C\end{array}$ CGGGTTGATAGGGTACCAATGTGCTTGTCATGATTTAGCCGGCCGTCGTGGCCCATTCGCTGAAATGACTATATCCCACA $\begin{array}{lllllllllllllllllllllllllllllllllll}G & L & I & G & Y & Q & C & A & C & H & D & L & A & G & R & R & G & P & F & A & E & M & T & I & S & H & T\end{array}$ CGTATGAATTGGAGAGCCTGTCCGGTGTTGTTGATGATGCTACTCTGGTGGCCAATCTAGGCTCTTTCCTGCTACCAATT

$\begin{array}{llllllllllllllllllllllllll}Y & E & L & E & S & L & S & G & V & V & D & D & A & T & L & V & A & N & L & G & S & F & L & I & P & I\end{array}$ CATTGTGAATATTCCCGTGTGGATCCCTCGCTCTCACCTTTCCATITGACTCAACCTCATCCTACGGATAGAGTGTCTGT

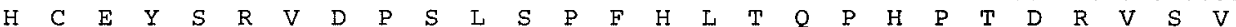
TGAGTCACTTCAAGCCGTCTGTGATACGTCCCTCCCCACTCACGTGTGTTACGATGACACGTACCACCAAGTGTTCGTAG $\begin{array}{lllllllllllllllllllllllllll}E & S & L & Q & A & V & C & D & T & S & I & P & T & H & V & C & Y & D & D & T & Y & H & Q & V & F & V & E\end{array}$ AGAACTCAGATTTCACTACTGATATCGATCACTTGACTTTGAAACAGTCCGATCTGATTCCGAAGGCAGATGGTGGTAAT

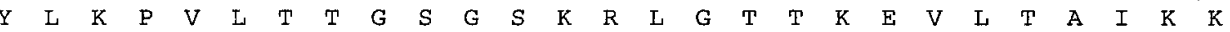
ACGTAATGCTGACGTTCCTGAACTGTCAGGTTCAGTTGATTTAACTCGCATCAGCCAGGCCGTGCGTAGAAGATTTAAAG AGTCATATTTTAACACCAATGCCTTAGCTCAAAGCAACTTCTTGAATGTCGTAGGTAACTTCCATGCTTATATGCAAAAA $\begin{array}{llllllllllllllllllllllllllllll}S & Y & F & N & T & N & A & L & A & O & S & N & F & L & N & V & V & G & N & F & H & A & Y & M & O & K\end{array}$ TGGGCCGCTTCTGGCCTTTCCTACGACGATCTACCCGACCTGCACGCCGAGAACCTGCAATTCTATGAGCACATGGTTAA W ATCCGATGTTAAACCAGTGGTAGCTGACACCCTGAACGTCGATAGCACTGTTCCGGCTACCATAACCTTCCACGCTAAAG $\begin{array}{llllllllllllllllllllllllllllll}S & D & V & K & P & V & V & A & D & T & \text { L } & N & V & D & S & T & V & P & A & T & I & T & F & H & A & K & G\end{array}$

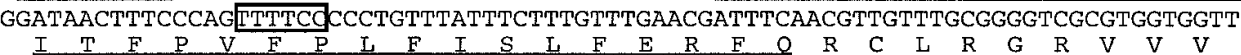
CCGGTGGGTAAGATTTCCTCCCTTGAGATGGACAATTTCTCAGTACTTAATAAATTTTGCTTGGAGATCGATTTGTCTAA

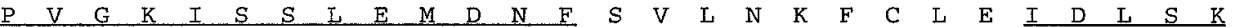
ATTCGATAAATCTCAAGGTGAGTTGCATCTAATGATTCAAGAAGAAATTCTGAATTTGTTAGGGTGTCCTGTTGACGTAT $\begin{array}{lllllllllllllllllllllllllllll}E & D & K & S & O & G & E & \text { L } & H & \text { L } & \text { M } & \text { I } & Q & E & E & \text { I } & \text { L } & N & \text { L } & \text { L } & G & \text { C } & \text { P } & \text { V } & \text { D } & \text { V } & S\end{array}$ CCAAGTGGTGGTGCGATTTTCACAGGTATTCCTACATTAAAGATAAGAGAGCTGGTGTGAGCATGCCGATAAGTTTCCAA

$\begin{array}{lllllllllllllllllllllllllllll}K & W & W & C & D & F & H & R & Y & S & Y & I & K & D & K & R & A & G & V & S & M & P & I & S & F & O\end{array}$ CGACGCACCGGAGACGCCTTCACCTATTTTGGTAACACTTTAGTGACAATGGCTITATTCTCCTGGTGTTATGACACTGA

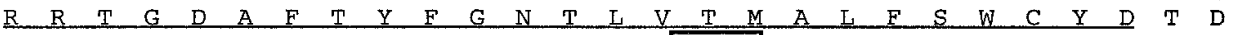
TCAGTTTGATCGCATGCTGTTTTCTGGGGATGACTCTCTAGCCTTTCDTGAACCCGATTGAAGGGAAATCGGATTGGT

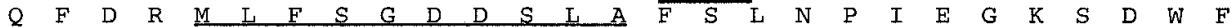
TCACTTCACTTTTTAATATGGAAGCAAAGAACATGGACCCCCCACTCCTTATATATGTTCTAAGTTTCTATTGACGGAT $\begin{array}{llllllllllllllllllllllllllll}T & S & L & F & N & M & E & A & K & N & M & D & P & P & T & P & Y & I & C & S & K & F & L & L & T & D\end{array}$ GAGTTGGGTAATACATTCTCCGTCCCCGATCCTTTACGTGAGCTGCAACGTTTGGGAACGAAGAAGATCCCTGATTGGGG

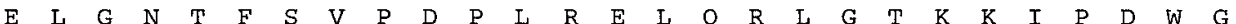
TCTTGACGAATCCTACCTAAGGGCCCATTTCATGAGTTTTGTTGATCGCCTGAAGTTCTTACCCAGAATGACTCACTATA $\begin{array}{lllllllllllllllllllllllllll}L & D & E & S & Y & I & R & A & H & F & M & S & F & V & D & R & I & K & F & I & P & R & M & T & H & Y & T\end{array}$ CTGTGGCGCAACTGACGACCTTCTATGAAATGAAGTACAAGAAATCTGGCGCTGAGTGTCATGCCATGCTCGGGGGATTC $\begin{array}{llllllllllllllllllllllllllll}V & A & Q & L & T & T & F & Y & E & M & K & Y & K & K & S & G & A & E & C & H & A & M & L & G & G & F\end{array}$ GCGAAGTATTCCACCAACTTCTCCATTTATAAGGAGCTTTACATCTCTCATCAAAAGCGTTTTAGCTTGATCAACTCGTA $\begin{array}{llllllllllllllllllllllllllll}A & K & Y & S & T & N & F & S & I & Y & K & E & L & Y & I & S & H & Q & K & R & F & S & L & I & N & S & Y\end{array}$ TCCTGACGATAACTTTGTAGTGGAAAGGAAACCTATCTTAAGGAGCAAGAAGGTAAAAAGGGTTAAGAAGAATGTCGAGT $\begin{array}{llllllllllllllllllllllllllll}P & D & D & N & F & V & V & E & R & K & P & I & L & R & S & K & K & V & K & R & V & K & K & N & V & E\end{array}$ GTCGAGCAAGTTCATATGAAGCTCCAAAAACTGGT GGAAAAACAGAAGTCAGCGDGCAACGCCACCGACAAAACAGGAA

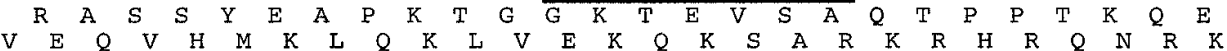
GGCTCGTGGACACAAGAGCCCAAGCGAGTTGAGGGGCCGGGAGCTCCGAGAAACCTTGTTTCTTTCTTTCCCAACCTCCGT

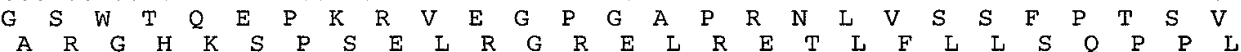
TGGGCCTCCTTTA $\overline{\overline{C G A T A T G G A T A A T}}$ CGCTGTGGCGAACCCTCATGTTCTCCCAGCTATACCTCCTGTGATGAAACAGAT

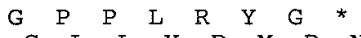

$\begin{array}{lllllllllllllllllllllllllll}G & \text { L } & L & Y & D & M & D & N & R & C & G & E & P & S & C & S & P & S & Y & T & S & C & D & E & T & D\end{array}$ TGGTTGGCTGGTAATGAGTGGTGTGAGGGTAGTTATTCCTGATCCCTGTCCCTTCGAGGATCGGGTGCT̄GAGTTGACĀGT

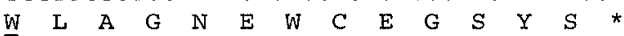
TACTGCTCTAAACTGTCTAAGTCACTAAACAGTTTACTGGT GAACGGGTTGTCCATCCAGCTTACGGCTAAAATGGTCAG TCCTACTCTAAAGGTAGGCCGAGT"TCTTACAAGGACTCGAGGTACTTTATATCATCTACTCCTGGTGATTGTGAAGAGC CGTGTACAATGTGCACATCAGGCCTCGGTACCCCCTCCTCGGAGGGTTTCCATAGGAGACCA
80

240

320

400

480

560

640

720

800

880

960

1040

1120

1200

1280

1360

1440

1520

1600

1680

1760

1840

1920

2000

2080

2160

2240

2320

2400

2480

2560

2640

2720

2800

2880

2942

Fig. 2. Nucleotide (nt) sequence of peanut stunt virus (PSV) strain BV-15 RNA2 cDNA. The predicted amino acid sequences of the 2a protein (the 2a gene is predicted from nt 81 to 2,585) and $2 \mathrm{~b}$ protein (the $2 \mathrm{~b}$ gene is predicted from nt 2,392 to 2,682) are indicated in the one letter code below the nt sequence. The eight conserved motifs characteristic of RNA-dependent RNA polymerases of positive-strand RNA viruses (8) are underlined. The amino acid residues conserved in cucumovirus $2 \mathrm{~b}$ proteins (9) are double underlined. The 40-nt domain conserved in the $3^{\prime}$-untranslated region of all cucumovirus RNA sequences is underlined, and the position of the only known variant nt in this highly conserved sequence is indicated with an arrow. The stop codons of open reading frames $2 \mathrm{a}$ and $2 \mathrm{~b}$ are indicated by an asterisk. The BV-15 RNA2 nt sequence complementary to the antisense primer PSVER2r (nt positions 2,436 to 2,455 ) is boxed. The sequences from nt 1,456 to 1,461 and from nt 1,884 to 1,889 of BV-15 RNA2 that are identical to the six nt at the 3' end of primer PSVER2r are boxed. 
PSV-BV-15 RNA2 would have higher sequence identity to PSV$\mathrm{W}$ than to PSV-ER, resulting in crossing of the two graph lines. However, no such crossing was observed. Throughout the entire RNA2 sequence of strain BV-15, the identity to PSV-ER RNA2 was always higher than to PSV-W, confirming that strain BV-15 RNA2 does not contain short regions derived from subgroup II strains.
Differentiation of PSV-BV-15 from PSV subgroup I and II strains based on RT-PCR analysis of RNA2. RT-PCR of gel-purified RNA2 from either PSV-ER or PSV-W, using a primer pair specific to PSV RNA2, generated a single RT-PCR product of the expected size $(1.2 \mathrm{kbp})$. Three RT-PCR products, however, were obtained with strain BV-15 RNA2 including the expected fragment of $1.2 \mathrm{kbp}$ and two smaller frag-

\section{A}

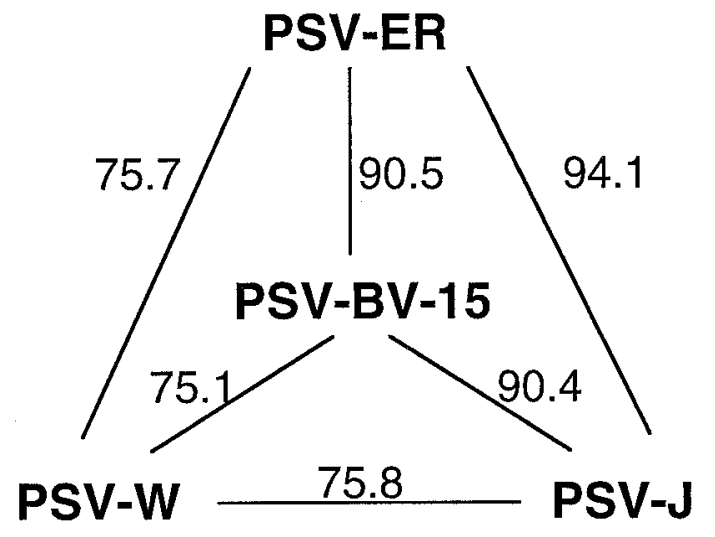

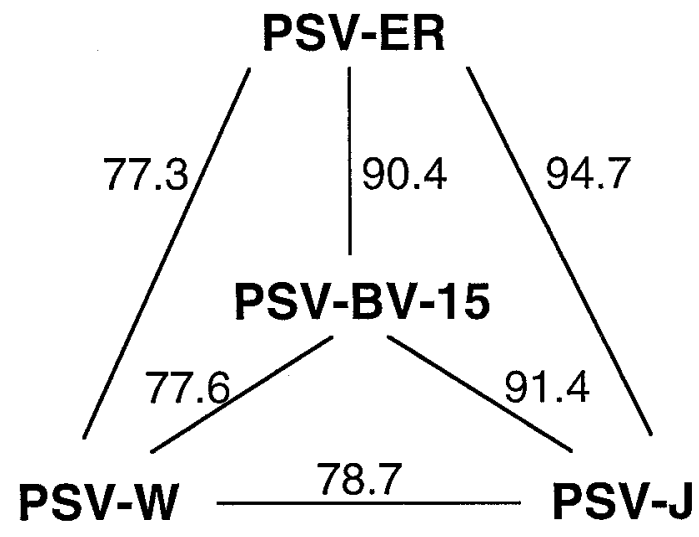

\section{$\%$ 2a protein amino acid sequence identity}

B

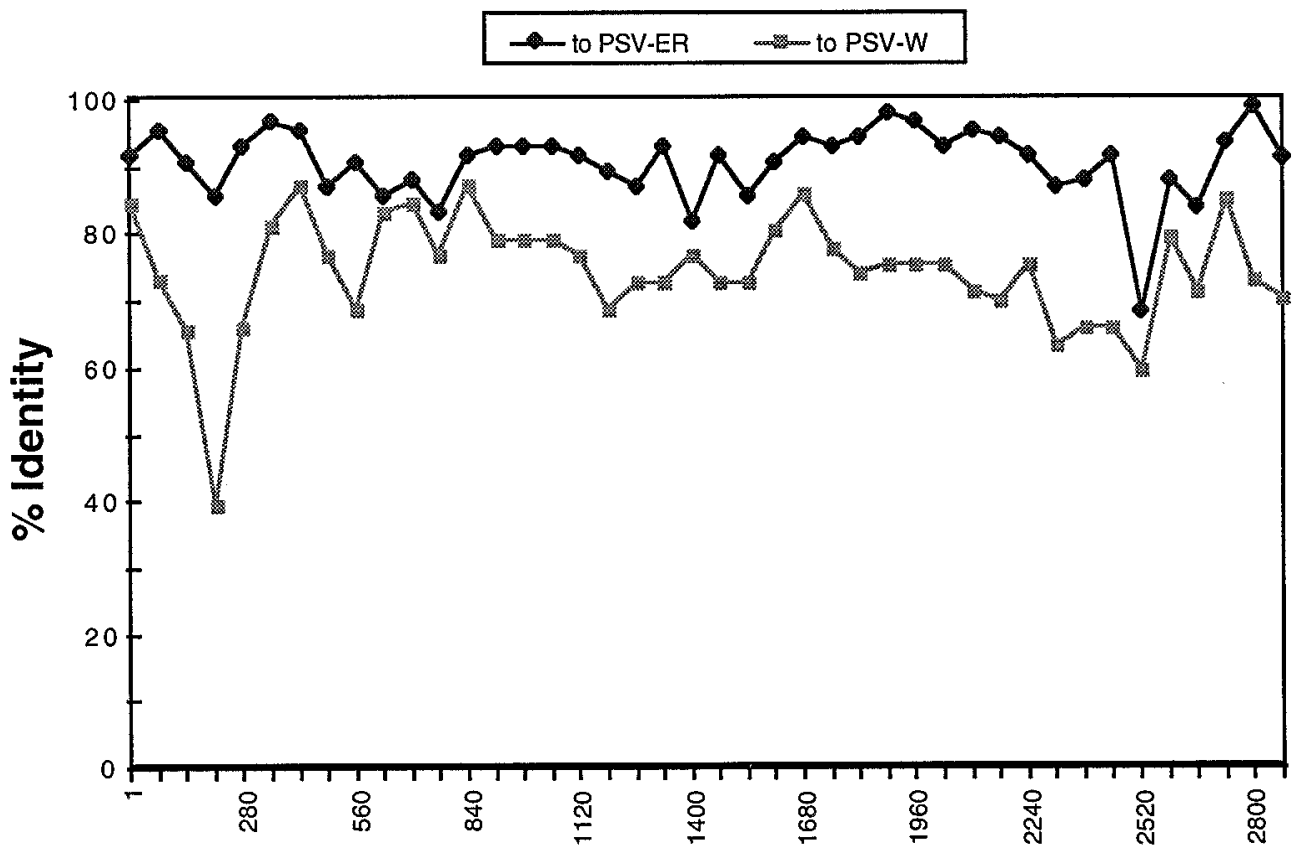

Nucleotide position

Fig. 3. Sequence comparison of RNA2 from peanut stunt virus (PSV) strain BV-15 with those of PSV subgroup I and II strains. A, Percent nucleotide (nt) and deduced amino acid sequence identity of RNA2 between PSV-BV-15 and subgroup I (PSV-ER and PSV-J) and II (PSV-W) strains. Numbers above connecting lines represent the percent identities between the RNA2 sequences (left panel) or 2a proteins (right panel) of the two strains being compared. B, Line chart representation of comparison of nt sequence identity between fragments of PSV-BV-15 RNA2 and corresponding fragments of PSV-ER RNA 2 ( $\bullet$ ) or PSV-W RNA 2 ( $)$. The nt sequence of RNA2 of PSV-BV-15 was divided into fragments of $70 \mathrm{nt}$ in length, with 25 nt overlapping each neighboring fragment to allow optimum sequence alignment and compared with the corresponding regions of PSV-ER or PSV-W with the GAP program of the University of Wisconsin GCG package. The values of percent identity ( $\mathrm{y}$ axis) of each region were plotted against the corresponding nt positions of PSV-BV-15 RNA 2 (x axis). Note that in each region of the sequence compared, the identity of PSV-BV-15 to PSV-W is consistently lower than to PSV-ER, and no crossing of the two lines was observed. 
ments of approximately 1.0 and $0.6 \mathrm{kbp}$ (Fig. 4A). The finding that the smaller two fragments were generated by PCR amplification of the 1.2-kbp RT-PCR product (16) suggested that the primer pair may anneal to alternative sites in PSV-BV-15
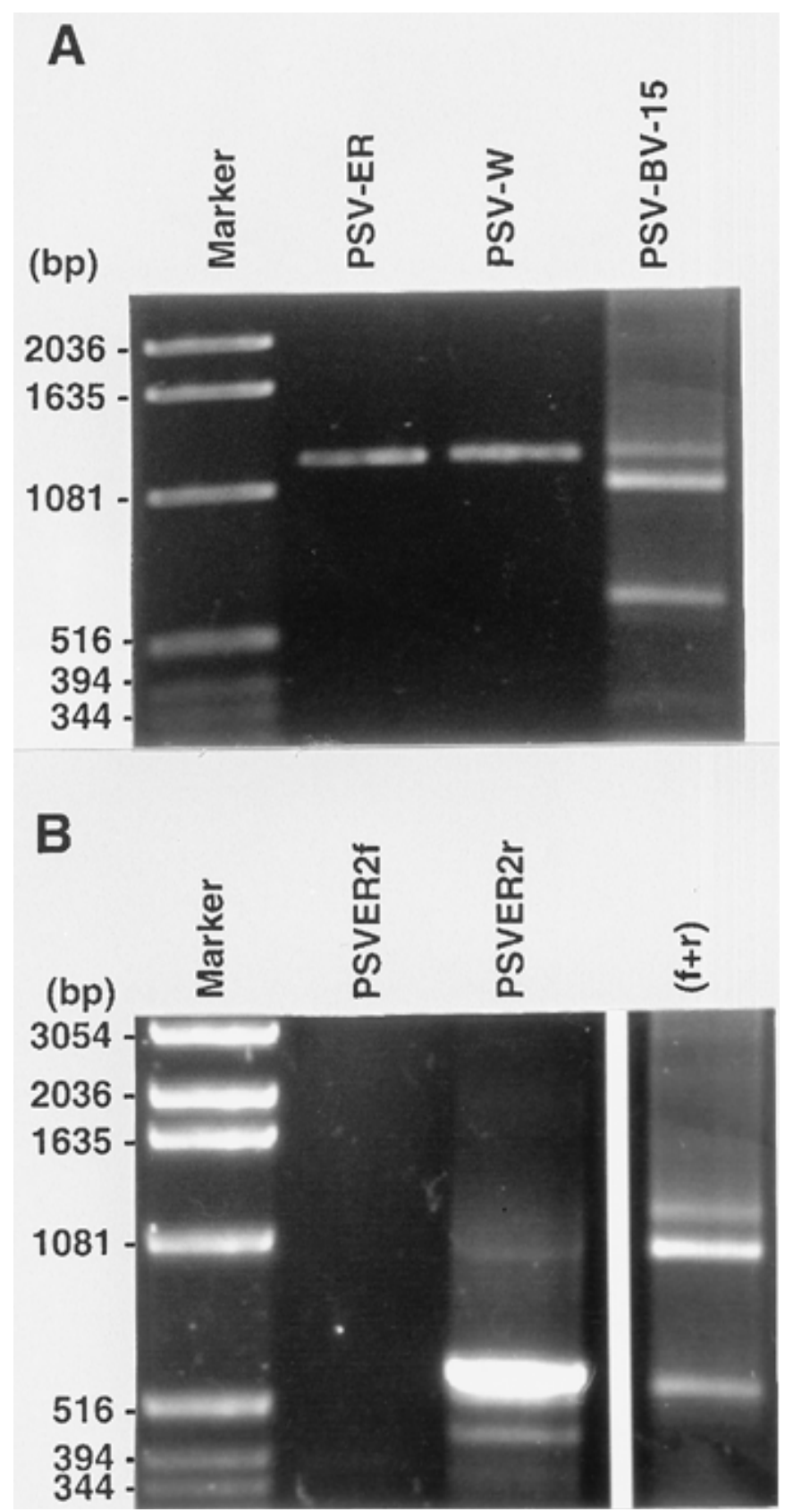

Fig. 4. Reverse transcription-polymerase chain reaction (RT-PCR) analysis of RNA from three strains of peanut stunt virus (PSV). A, The RT-PCR products of RNA2 from PSV-ER, PSV-W, and PSV-BV-15 (the names of the virus strains are indicated above each lane) were visualized by $1 \%$ agarose gel electrophoresis and ethidium bromide staining. The marker lane contains the $1-\mathrm{kb}$ ladder with the size of each fragment (in base pairs) indicated on the left. The primers used in RT-PCR (PSVER2f and PSVER2r) are specific for PSV RNA2 and are predicted to prime the amplification of a product of $1,171 \mathrm{bp}$ in length. Note that two additional RT-PCR products of approximately 0.6 and $1.0 \mathrm{kbp}$ were generated when PSV-BV-15 RNA 2 was used as a template. B, RT-PCR analysis of RNA2 of PSV-BV-15 using single primers as compared with using a pair of primers. The RT-PCR products generated when primer PSVER2f alone (lane PSVER2f), PSVER2 $r$ alone (lane PSVER2r), or the two primers together (lane $f+r$ ) were used to direct the amplification PSV-BV-15 RNA2 were visualized by $1 \%$ agarose gel electrophoresis and ethidium bromide staining. The marker lane is the same as in $\mathbf{A}$. Note that the $0.6-$ and $1.0-\mathrm{kbp}$ fragments are amplified in reactions primed with PSVER2r alone.
RNA2. To test this possibility, the PCR reaction was performed with a single primer, either PSVER2f or PSVER2r, using cDNA of PSV-BV-15 RNA2 as a template. The results showed that PSVER2r alone directed the amplification of the 0.6- and 1.0-kbp PCR products (Fig. 4B, lane PSVER2r), whereas no products were generated when the PSVER2 $\mathrm{f}$ oligonucleotide was used alone (Fig. 4B, lane PSVER2f). The $0.6-\mathrm{kbp}$ PCR product was cloned and sequenced (data not shown); its sequence was found to correspond to PSV-BV-15 RNA2 sequence from nt 1,884 to 2,454 . The nt sequence of the reverse primer, PSVER2r (complementary to $\mathrm{nt}$ positions 2,436 to 2,455 in PSV-BV-15 RNA2; Fig. 2, boxed sequence), is present at both ends of the 0.6-kbp PCR fragment. Examination of the nt sequence of PSV-BV-15 RNA2 revealed that the six nt at the $3^{\prime}$ end of primer PSVER2 $\mathrm{r}$ are identical to the sequences from nt 1,456 to 1,461 and from nt 1,884 to 1,889 of BV-15 RNA2 (Fig. 2, boxed sequences). Thus, the origin of the additional PCR products of approximately 0.6 and $1.0 \mathrm{kbp}$ may be explained by alternative site priming in the PCR reaction of PSV-BV-15 RNA2.

\section{DISCUSSION}

Previous studies have provided convincing serological and molecular evidence that RNA3 of PSV-BV-15 is derived from a PSV subgroup I strain $(6,16)$. This study presents conclusive evidence that PSV-BV-15 RNA1 is derived from a subgroup II strain and that RNA2 is derived from a subgroup I strain, thus establishing that strain BV-15 is a natural reassortant between PSV subgroup I and II strains. Northern hybridization assays using a cloned probe to RNA1 of PSV-W (subgroup II) showed that PSV-BV-15 RNA1 hybridized strongly with the probe, confirming an earlier proposal based on lack of hybridization of strain BV-15 RNA1 to a cloned RNA1 probe from a subgroup I strain (16). The complete nt sequences of RNA2 from PSV-BV-15 (this study) and from representative strains of subgroups I and II (PSV-ER and PSV-W, respectively) have been determined (C.-C. Hu and S. A. Ghabrial, unpublished data). The availability of these sequences in our laboratory as well as that of PSV-J (7) allowed us to carry out sequence comparison analysis that clearly indicated that RNA2 from strain BV-15 is closely related to that of subgroup I strains $(90.5$ and $75 \%$ sequence identities to subgroup I and II strains, respectively). The finding that the percent identity between the RNA2 sequences of strains BV-15 and ER is not much higher than $90 \%$ may explain why PSV-BV-15 RNA2 did not hybridize strongly with the PSV-ER RNA2-specific probe (Fig. 4 in literature citation 16). It is known that efficient detection of hybridization, under the high stringency conditions used, requires that the target sequences have at least $90 \%$ identity to the probe (10).

The possibility that BV-15 RNA2 may still contain short regions derived from subgroup II strains (i.e., a recombinant) was investigated and ruled out. Therefore, strain BV-15 RNA2 is entirely derived from a subgroup I strain and the uncertainty about its origin, brought up in a previous study (16), can now be dismissed.

Knowledge of the complete nt sequences of PSV-BV-15 RNA2 and of the 0.6-kbp RT-PCR product made it possible to clarify the unusual RT-PCR profile produced with strain BV-15 RNA2 as a template (16). The origin of the 0.6- and 1.0-kbp RT-PCR products can now be explained based on the presence of alternative binding sites in the RNA2 sequence of PSV-BV-15, but not in that of the other strains. Furthermore, the previously proposed possibility of the presence in strain BV-15 of a heterogeneous population of RNA2 molecules (16) appears unlikely, since the sequence of the 0.6-kbp RT-PCR product is identical to the corresponding region in the cDNA clone of full-length RNA2. The distinguishing features of BV-15 RNA2 (generation of three PCR products instead of one and the ability to generate the small products using a single primer) may be exploited in genetic studies involving PSV-BV-15 RNA2. 
PSV-BV-15 has been well characterized biologically, serologically, and at the molecular level (2,6,16, this study). It represents the first well-documented example of a naturally occurring intraspecific cucumovirus reassortant strain. White et al. (27) have recently reported the isolation of an apparent interspecific reassortant from common bean in Chile, designated CMV-PA. Based on Northern hybridization analysis, CMV-PA appears to be an interspecific reassortant having PSV RNA1 and RNA2 and CMV subgroup II RNA3 (27). CMV-PA, however, has not been characterized serologically or by nt sequence analysis. Naturally occurring reassortants such as PSV-BV-15 and CMV-PA may become established in the virus population and may contribute to the rapid genetic variation of cucumoviruses with significant epidemiological implications. Previous studies with artificial reassortants indicated that the inability to form viable reassortants between RNA1 and RNA2 from different viruses may be employed as a criterion for classification of cucumovirus strains into three separate species: CMV, PSV, and TAV $(17,18,20)$. Therefore, the fact that strain $\mathrm{BV}-15$ is a viable reassortant supports the placement of the two virus strains from which PSV-BV-15 RNA1 and RNA2 are derived into two subgroups under the same virus species (PSV), instead of placing them into two different species.

Naturally occurring reassortants such as PSV-BV-15 as well as laboratory constructed reassortants and recombinants (21) provide valuable tools for studies on identifying viral gene functions. For example, RNA1 of strain BV-15 is derived from a subgroup II strain closely related to PSV-W (this study), and both strains PSV$\mathrm{W}$ and PSV-BV-15 have recently been shown to support little or no satRNA replication in several host plants (16). Because all PSV subgroup I strains tested to date support satRNA replication efficiently (16), the satRNA support function may be mapped to RNA1. Strain BV-15 should be useful for studies on PSV-host interactions and on mapping PSV gene functions.

In conclusion, we have established that PSV-BV-15 is a natural reassortant between PSV subgroup I and II strains. The complete nt sequence of BV-15 RNA2 has been determined, and sequence comparison analysis indicates that it is entirely derived from a subgroup I strain. Furthermore, a RT-PCR procedure is proposed for differentiating this natural reassortant from PSV subgroup I and II strains.

\section{ACKNOWLEDGMENTS}

This research was funded by a grant from The University of Kentucky Tobacco and Health Research Institute (5-41124) and is published as Journal Series paper 97-12-110 of the Kentucky Agricultural Experiment Station.

\section{LITERATURE CITED}

1. Devereux, J., Haeberli, P., and Smithies, O. 1984. A comprehensive set of nucleotide sequence analysis programs for the VAX. Nucleic Acids Res. 12:387-395.

2. Diaz-Ruiz, J. R., and Kaper, J. M. 1983. Nucleotide sequence relationships among thirty peanut stunt virus isolates determined by competition hybridization. Arch. Virol. 75:277-281.

3. Ding, S.-W., Anderson, B. J., Haase, H. R., and Symons, R. H. 1994. New overlapping gene encoded by the cucumber mosaic virus genome. Virology 198:593-601.

4. Ghabrial, S. A., Pickard, C. M., and Stucky, R. E. 1977. Identification and distribution of virus diseases of soybean in Kentucky. Plant Dis. Rep. 61:690-694.

5. Gubler, U., and Hoffman, B. J. 1983. A simple and very efficient method for generating cDNA libraries. Gene 25:263-269.
6. Hu, C.-C., Aboul-Ata, A. E., Naidu, R. A., and Ghabrial, S. A. 1997. Evidence for the occurrence of two distinct subgroups of peanut stunt cucumovirus strains: Molecular characterization of RNA3. J. Gen. Virol. 78:929-939.

7. Karasawa, A., Kazuhiro, N., Kakutani, T., Minobe, Y., and Ehara, Y. 1992. Nucleotide sequence analyses of peanut stunt cucumovirus RNAs 1 and 2. J. Gen. Virol. 73:701-707.

8. Koonin, E. V., and Dolja, V. V. 1993. Evolution and taxonomy of positive strand RNA viruses: Implications of comparative analysis of amino acid sequences. Crit. Rev. Biochem. Mol. Biol. 28:375-430.

9. McGarvey, P., Tousignant, M., Geletka, L., Gellini, F., and Kaper, J. M. 1995. The complete nucleotide sequence of a cucumber mosaic virus from Ixora that is deficient in the replication of satellite RNAs. J. Gen. Virol. 76:2257-2270.

10. Memelink, J., Swords, K. M. M., Staehelin, L. A., and Hoge, J. H. C. 1994. Southern, northern and western blot analysis. Pages F1:1-23 in: Plant Molecular Biology Manual, 2nd ed. S. B. Gelvin and R. A. Schilperoort, eds. Kluwer Academic Publishers, London.

11. Mink, G. I. 1972. Peanut stunt virus. In: CMI (Commonw. Mycol. Inst.)/AAB (Assoc. Appl. Biol.) Descriptions of Plant Viruses No. 92.

12. Mink, G. I., Silbernagel, M. J., and Saksena, K. N. 1969. Host range, purification, and properties of the western strain of peanut stunt virus. Phytopathology 59:1625-1631.

13. Naidu, R. A., Collins, G. B., and Ghabrial, S. A. 1991. Symptom-modulating properties of peanut stunt virus satellite RNA sequence variants. Mol. Plant-Microbe Interact. 4:268-275.

14. Naidu, R. A., Collins, G. B., and Ghabrial, S. A. 1991. Nucleotide sequence analysis of a cDNA clone encoding the coat protein gene of peanut stunt virus. Plant Mol. Biol. 17:175-177.

15. Naidu, R. A., Collins, G. B., and Ghabrial, S. A. 1992. Peanut stunt virus satellite RNA: Analysis of sequences that affect symptom attenuation in tobacco. Virology 189:668-677.

16. Naidu, R. A., Hu, C.-C., Pennington, R. E., and Ghabrial, S. A. 1995. Differentiation of eastern and western strains of peanut stunt cucumovirus based on satellite RNA support and nucleotide sequence homology. Phytopathology 85:502-507.

17. Palukaitis, P., Roossinck, M. J., Dietzgen, R. G., and Francki, R. I. B. 1992. Cucumber mosaic virus. Adv. Virus Res. 41:281-348.

18. Rao, A. L. N., and Francki, R. I. B. 1981. Comparative studies on tomato aspermy and cucumber mosaic viruses. VI. Partial compatibility of genome segments for the two viruses. Virology 114:573-575.

19. Roossinck, M. J., Sleat, D., and Palukaitis, P. 1992. Satellite RNAs of plant viruses: Structures and biological effects. Microbiol. Rev. 56:265279.

20. Rybicki, E. P. 1995. Bromoviridae. Pages 450-457 in: Virus Taxonomy: Sixth Report of the International Committee on Taxonomy of Viruses. F. A. Murphy, C. M. Fauquet, D. H. L. Bishop, S. A. Ghabrial, A. W. Jarvis., G. P. Martelli, M. A. Mayo, and M. D. Summers, eds. SpringerVerlag, New York (Arch. Virol. suppl. 10).

21. Salanki, K., Carrere, I., Jacquemond, M., Balazs, E., and Tepfer, M. 1997. Biological properties of pseudorecombinants and recombinant strains created with cucumber mosaic virus and tomato aspermy virus. J. Virol. 71:3597-3602.

22. Sambrook, J., Fritch, E. F., and Maniatis, T. 1989. Molecular Cloning: A Laboratory Manual. 2nd ed. Cold Spring Harbor Laboratory, Cold Spring Harbor, NY.

23. Sanger, F., Nicklen, S., and Coulson, A. R. 1977. DNA sequencing with chain-terminating inhibitors. Proc. Natl. Acad. Sci. U.S.A. 74:5463-5467.

24. Shen, W., and Waye, M. M. Y. 1988. A novel method for generating a nested set of unidirectional deletion mutants using mixed oligodeoxynucleotides. Gene 70:205-211.

25. Sippel, A. E. 1973. Purification and characterization of adenosine triphosphate-ribonucleic acid adenyl transferase from Escherichia coli. Eur. J. Biochem. 37:31-40.

26. Vieira, J., and Messing, J. 1987. Production of single stranded plasmid DNA. Methods Enzymol. 153:3-11.

27. White, P. S., Morales, F., and Roossinck, M. J. 1995. Interspecific reassortment of genomic segments in the evolution of cucumoviruses. Virology 207:334-337.

28. Xu, Z., Barnett, O. W., and Gibson, P. B. 1986. Characterization of peanut stunt virus strains by host reactions, serology, and RNA patterns. Phytopathology 76:390-395. 